\title{
OPTIMIZATION OF FLOCCULAR CLEANING AND DRAINAGE OF THIN DISPERSED SLUDGES
}

\author{
Oleksii Shestopalov ${ }^{1}$ \\ shestopalov.it@khpi.edu.ua \\ Oleksandr Briankin \\ bryankin@i.ua \\ Nadegda Rykusova ${ }^{1}$ \\ n_rykusova@ukr.net \\ Oksana Hetta \\ oksanagetta21@gmail.com \\ Valentina Raiko ${ }^{1}$ \\ raiko.hpi@gmail.com \\ Musii Tseitlin ${ }^{1}$ \\ michelzeitlin@gmail.com
}

${ }^{1}$ Department of chemical technique and industrial ecology

National Technical University "Kharkiv Polytechnic Institute"

2 Kyrpychova str., Kharkiv, Ukraine, 6100

\begin{abstract}
The efficiency of solid phase retention and dehydration of finely dispersed products of a coal processing plant and a metallurgical enterprise on the module for cleaning and dewatering sludge is investigated. A technique for selecting the operating parameters of equipment based on the determination of the strength criterion of flocs is proposed. A methodology for technological tests has been developed to control the flocculation process and optimize the flow of flocculant depending on the concentration of the solid phase.

Industrial tests on the module for wastewater treatment and sludge dewatering using flocculants proved the effectiveness of the developed methodology. It is shown that the conditions for conducting tests on flocculation should correspond to the operating conditions of the circuit apparatus for cleaning and dewatering sludge. These conditions include sludge performance, sludge flow rate in the cross section of pipes and apparatuses, and the flow time from the flocculator to the centrifuge. During the testing of the Module, the solids retention efficiency of $97-99 \%$ was achieved with the strength criteria of flocs in front of a centrifuge of 2-2.5 mm/s.

The conditions for the high efficiency of the apparatus chain are the optimization of the aggregation process itself. It is revealed that for the formation of strong flocs it is necessary to regulate the concentration of the solid phase. For coal sludge, the concentration of the solid phase before the flocculant is fed must be maintained no higher than 50-60 g/l, and for gas treatment sludge - no higher than $20-25 \mathrm{~g} / \mathrm{l}$. Correction of the concentration of sludge before the flocculator is possible by diluting it with clarified water to the optimum concentration for aggregation.

It is found that the moisture content of the sediment and the efficiency of the retention of the solid phase depend on the strength criterion of the flocs. Therefore, the optimization of the flocculant flow rate is possible by controlling and the residual floccule deposition rate after mechanical action in front of the dewatering equipment. The flocculant flow rate must be adjusted depending on the concentration of the solid phase in the sludge to achieve the desired criterion for the strength of the flocs.
\end{abstract}

Keywords: fine sludge, aggregation, solid phase retention efficiency, sludge dewatering degree, centrifuge, flocculation.

DOI: $10.21303 / 2461-4262.2020 .001239$

\section{Introduction}

The modern water-sludge scheme of water circulation cycles of many enterprises (metallurgical enterprises, coal processing plants, etc.) is heavily overloaded with liquid waste. As a result of this, the efficiency of the radial sedimentation tanks and their productivity in clarified water decreases, the load on the filter presses in the thickened product increases. As a result, there is a short- 
age of water for the needs of the enterprise, which reduces the efficiency of the equipment. The lack of effective equipment for the complete capture of fine-grained products necessitates the discharge of the thinnest part of the sludge into the external sludge sumps and sludge collectors. Annually in Ukraine alone, discharge to the sludge storage facilities (on solid) is 3.0-4.0 million tons. [1]. The accumulation of mining waste, coal preparation, metallurgy leads not only to operating costs for the maintenance of sludge collectors, but also to secondary environmental pollution [2].

The purpose of sludge cleaning and dewatering is the optimal separation of the liquid and solid phases with the highest possible purity of the liquid phase and the lowest humidity of the solid phase. The problem of dehydration of fine suspensions is associated with the efficiency of the extraction of solids in the precipitate, the amount of solid phase in the liquid separation product (centrate, filtrate).

The main indicators of the efficiency of the dewatering equipment are: sludge moisture, the efficiency of the retention of the solid phase in the sludge, the solids content in the liquid separation product. The accumulation of finely dispersed particles in the sludge and the increase in their concentration make it difficult to achieve satisfactory values of these indicators.

The use of one or another equipment for dehydration depends mainly on the dispersion (sieve or particle size distribution) of the solid phase of the sludge, as well as the advisability of using sludge as a commercial product.

In world practice, there is a tendency to increase the specific gravity of the use of mechanical methods for dewatering sludge and sewage sludge of various origins [3]. This is due to the continuous increase in the cost of energy resources and the corresponding rise in price of alternative mechanical - thermal dehydration methods [4].

Among the most common methods for dewatering thin sludges and silts is their thickening and subsequent filtering. Dehydration is carried out on filter presses using flocculants [5, 6], filtration under vacuum $[7,8]$ or using electro-osmosis to remove capillary moisture $[9,10]$.

The main disadvantage of filters is the need for their constant washing with clean water, directed, most often, from sludge settlers. When overloading sedimentation tanks in the solid phase, the load on the filters in the thickened product increases, which leads to a decrease in the efficiency of their work. Therefore, an important task is to reduce the circulating load on the solid phase in the water-sludge scheme. This can be achieved by using additional equipment that traps and dehydrates part of the solid phase in front of sedimentation tanks and filters.

The practice of using precipitation centrifuges confirms the effectiveness of their work in the dehydration of finely dispersed products of various ash contents [11, 12].

The most important pulp parameters that affect the centrifuge's dewatering efficiency are particle size, solids content and suspension. Typically, the amount of ultra-thin material is determined by the content of particles of class less than $0.04 \mathrm{~mm}$ in the total amount of solid in the diet. According to practical data [13], with the growth of ultrafine fractions, the humidity of the precipitate also increases, which leads to the inability to capture small particles. It is known that the coal fraction is distributed unevenly by size classes and the finest fractions (less than $0.05 \mathrm{~mm}$ ) are represented mainly by soft clay [1]. The discharge of ultrafine fractions of high ash content removes up to $50 \%$ moisture from the sediment. Therefore, it is better to discard ultrafine material, which subsequently will not lead to significant losses due to the economic inexpediency of the extraction of the solid phase $[14,15]$.

In addition to the content of fine fractions (less than 20 microns), other factors affect the process of sludge dehydration to a greater or lesser extent, which can be divided into the following groups:

- properties of sludge: type of dispersed phase and medium, their density;

- design parameters of equipment (filters, centrifuges) and their operation mode;

- production conditions: solids content in food, separation factor indicator (for centrifuges), sizes of dehydration zones, duration of dehydration, specific equipment throughput, and others;

- ways to intensify the dehydration process: the use of flocculants, regulation of the concentration or dispersion of the solid phase in the nutrition of the dehydration equipment, optimization of aggregation conditions, etc. [16]. 
In turn, the use of flocculants to intensify the processes of aggregation and sedimentation of sludge has a number of features [17]. The formation of aggregates during flocculation consists of the following stages: destabilization of the dispersed system; collision of particles and polymers, adhesion of the polymer to the surface of the particles; aggregate growth phases and their subsequent destruction [18]. From the point of view of flocculation efficiency and the corresponding process parameters (phase separation of liquid and solid phases), aggregates can be characterized by their size, shape, density, porosity, compressive strength and deformability. The efficiency of separation of flocs and the liquid phase depends on the strength of the flocs (the adhesion force of particles in the floccule), which depends on many factors: the properties of the solid phase (density, ash, chemical composition, concentration, dispersion), the properties of the liquid ( $\mathrm{pH}$, dissolved salts) and used flocculant. For a particular production, some of the indicators of wastewater that affect the efficiency of flocculation remain on average unchanged, and some can change over time. Most often, during the day, the concentration of the solid phase in the wastewater changes, which has the greatest effect on the efficiency of flocculation. Under industrial conditions, all factors and theories described in the analysis [17] that affect the strength of aggregates cannot be taken into account. In $[16,19]$, it is proposed to use the integral strength indicator - the residual velocity of flocs after mechanical or gyromechanical action. Such a residual deposition rate qualitatively characterizes the density of flocs, their size and resistance to external destructive influences.

Most of the factors affecting the efficiency of the process for cleaning and dewatering sludge are technological and specific to a particular type of production. The processes of separation of suspensions have a complex regularity, and theoretical propositions are usually obtained for idealized models and do not take into account the influence of all existing factors. Therefore, when solving production problems, the use of generalized laws is often difficult. Aggregation processes during coagulation and flocculation, the formation and destruction of formed aggregates during the transportation of fine sludge in various apparatuses are still not well understood. Therefore, the experimental and theoretical study of these processes in relation to each type of sludge and equipment is an urgent task.

In order to increase the efficiency of cleaning and dehydration of fine liquid waste, a smallsized module for wastewater treatment and waste dehydration is tested on the basis of a thin-layer sedimentation tank, modernized sedimentation centrifuges using flocculants. The use of such a module will allow unloading radial thickeners and filter presses of the water cycle of enterprises by cleaning and subsequent dewatering of industrial sludge. This will ensure the uninterrupted operation of the water cycle due to the return of additional clean water to the system.

\section{The methodology for the study of flocculation treatment of industrial wastewater}

\section{1. Description of the module for cleaning and dewatering of sludge}

In the module, sludge is purified from suspended solids by settling in a thin-layer sump. The intensification of the processes of sedimentation of suspended solids in the sump occurs due to the use of flocculants and preliminary preparation of sludge water according to the concentration and particle size distribution of suspended solids. The clarified product of a thin-layer sump can be used in production to feed a water circuit. The thickened product of a thin-layer sump is dehydrated in a precipitation centrifuge.

The circuit diagram of the apparatus of the wastewater treatment module and waste dehydration (hereinafter referred to as the module) in a complete set is shown in Fig. 1.

The damping-classifying tank is designed to receive wastewater from various sources and averaging the concentration, as well as classifying the solid phase of the pulp (removal of large fractions of more than $3 \mathrm{~mm}$ ). Additionally, it is possible to create conditions for a satisfactory subsequent flocculation. For example, adjusting the concentration of solid phase in the sludge by dilution with water.

A flocculator is a device for organizing and processes of flocculation and aggregation of finely divided solid fractions in order to obtain flocs of the required size in terms of sedimentation rate and strength in terms of deposition rate. The flocculator is a pipe with two static mixers for introducing the flocculant into two portions. The first portion of the flocculant is introduced into 
the flocculator to adhere the polymer and form small flakes, which subsequently flocculated after the second portion of the flocculant is introduced.

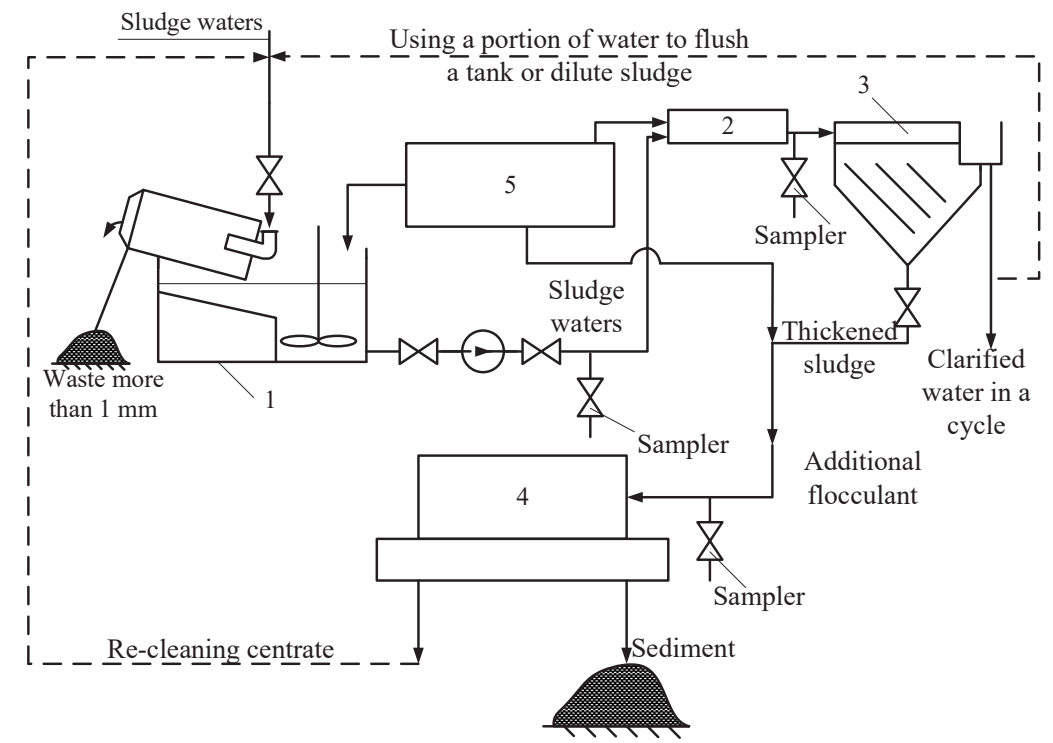

$a$

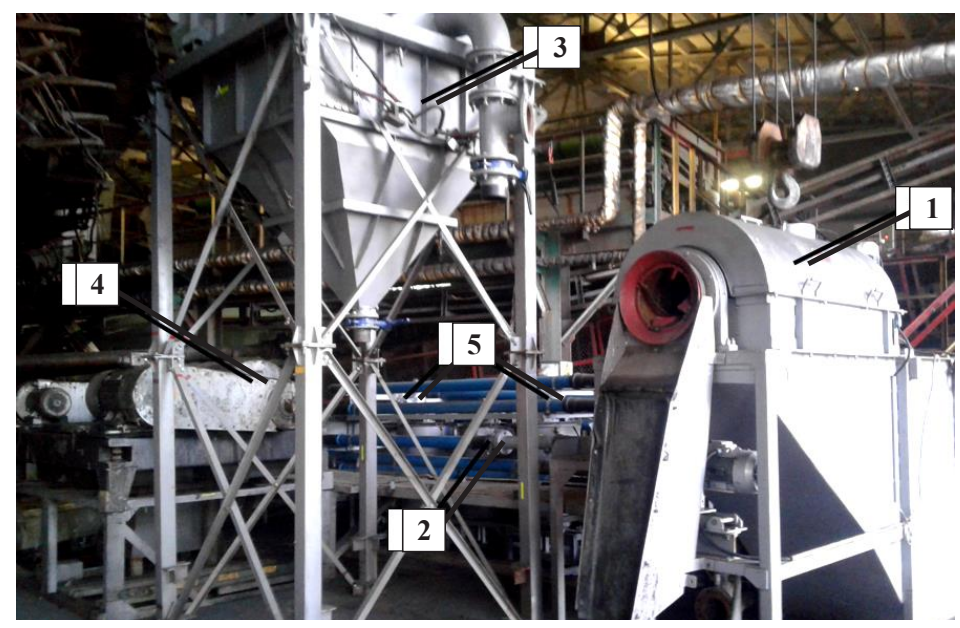

$b$

Fig. 1. The module for wastewater treatment and sludge dewatering: $a$ - circuit diagram of the module apparatus; $b$ - photograph of the mounted module in industrial tests: 1 - damping-classifying capacity; 2 - flocculator; 3 - thin layer sump; 4 - centrifugal unit; 5 - flocculant preparation station

Polyelectrolytes based on polyacrylamide of the anionic type ECOFLOC A-19 (for wastewater treatment of a coal preparation plant) and cationic type ECOFLOC K-7 (for wastewater treatment of a metallurgical plant) is used as flocculants.

Thin-layer sedimentation tank is designed to separate the pulp into clarified water and condensed product. The thickened product of a thin-layer sedimentation tank is fed to a centrifugal unit for dewatering.

A centrifugal unit of the OGSh type (NTC Ekomash, Kharkiv) is a precipitation-type centrifuge with a biconical rotor. The centrifuge is equipped with two drives to change the conveyor capacity of the auger and, thus, adjust sludge moisture and solid sludge productivity. The design of the centrifuge allows to reduce the destructive effect on flocs [16], to carry out reflocculation of the 
incoming condensed product (introducing an additional third portion of the flocculant before the centrifuge), providing the most clarified centrate (suspended particles $1-2 \mathrm{~g} / \mathrm{l}$ ).

The adjustment of the technology of the Module is preceded by a laboratory study of sludge water, according to the results of which the operating mode of the devices of the Module is configured. The measurement of solid content, the adjustment of the supply of flocculants and pulp are carried out manually.

\section{2. Methodology for setting the module for cleaning and dewatering of sludge the sludge \\ 2. 2. 1. Determination of the dependence of the concentration of solid phase in}

The sludge supplied for treatment is reverse cycle water contaminated with a finely divided solid phase with a class fraction of less than 40 microns $80-90 \%$ for a coal preparation plant and 85-93\% for a metallurgical plant. The concentration of the solid phase during the tests ranged up to $30 \mathrm{~g} / 1$ for the metallurgical enterprise and 30-90 g/1 for the coal preparation plant.

Due to the fact that the efficiency of aggregation due to flocculation depends on the concentration of the solid phase, it is necessary to constantly know the concentration of suspended solids in the cleaned sludge. Quickly determine the concentration of the solid phase in a production environment by weighing the volume of sludge and determining its density. The more solid phase in the sludge, the more its weight will deviate from the weight of water. But to obtain the correct data on the correspondence of the weight of a certain concentration of the solid phase for a given sludge, it is necessary to build the dependence of the weight of the sample of the sludge (or density) on the concentration:

$$
\mathrm{C}=f(m)
$$

where $C$ - the concentration of the solid phase in the wastewater of this production, $\mathrm{g} / \mathrm{l} ; \mathrm{m}$ - weight of 1 liter of wastewater or sludge from this production, $\mathrm{g}$.

This is achieved by repeatedly weighing the samples of the sludge, diluting it and analyzing its solid phase content.

\section{2. 2. Conducting flocculation tests and determining the costs of flocculants}

Technological tests allow to quickly determine the technological modes of setting the equipment chain. In the course of research, the conditions for the aggregation of fine fractions by flocculation, the rate of deposition of aggregates before and after mechanical stress $\left(V_{1}\right.$ and $\left.V_{2}\right)$, as well as the partial recovery of aggregates are determined.

Thus, a mixture of wastewater with a flocculant is prepared, which can withstand hydrodynamic loads during transport to the centrifuge and inside it until it reaches the inside of the rotor space.

When determining the deposition rate of flocs, the duration and intensity of mixing during the test are measured, and then these parameters are implemented in the Module.

In particular, the floccule deposition rates are determined: $V_{1}$ is the floccule deposition rate after completion of flocculation and other methods of processing stock; $V_{2}$ is the deposition rate of flocs after hydromechanical action on the condensed precipitation product. Moreover, the intensity and time of hydromechanical impact in the test for flocculated aggregates should correspond to the actual conditions on the Module. The adequacy of the laboratory test to real conditions can be controlled by comparing the sedimentation rates of the flocs to the sump and before the centrifuge.

According to the methodology described in publications [19-21], flocculant expenditures are tested to achieve $V_{1} \geq 6-7 \mathrm{~mm} / \mathrm{s}$ (the condition for the effective operation of this thin-layer sedimentation tank); $V_{2} \geq 2-3 \mathrm{~mm} / \mathrm{s}$ (condition for the effective operation of this centrifuge).

As a result of the tests, the dependences of the change in the floccule deposition rate on the concentration of the solid phase and the dependence of the flocculant consumption on the concentration of the solid phase are built to achieve the desired speed $\left(V_{1}\right.$ and $\left.V_{2}\right)$ : 


$$
Q=f(C, V),
$$

where $C$ - the concentration of the solid phase in wastewater, g/l; $Q$ - flocculant consumption per unit mass of the solid phase, $\mathrm{g} / \mathrm{t}$.

Knowing this relationship allows to optimize the dosage of the flocculant in such a way that the necessary values of the criteria $V_{1}$ and $V_{2}$ are achieved, eliminating the excessive flocculant consumption.

According to the test results, the dosage of flocculants is calculated to achieve the indicated deposition rates, as well as the flocculant supply valves are set to the working position with a given flow rate.

\subsection{Control of quality indicators}

To control the quality indicators of the module equipment at the inlet and outlet of each device, samples of technological environments are taken. The effectiveness of the module is evaluated by the following indicators:

- a sample of clarified water after the sump;

- a sample of the centrate after a centrifuge;

- samples of humidity of the dehydrated sludge by centrifugal unit.

The module is sampled after a receiving and dosing tank in order to determine the concentration of the solid phase at the inlet. The sampling of food after the addition of flocculants is carried out in front of a thin-layer sump to determine $V_{1}$ and $V_{2}$. The sampling of the thickened sludge of a thin-layer sump is carried out before centrifugal unit in order to control the degree of thickening and $V_{2}$. The sampling of the centrate is carried out in a centrifugal unit in order to determine the degree of solid phase retention by the Module. The efficiency of the capture of the solid phase in the precipitate is estimated by the formula:

$$
\eta=\frac{C_{i n}-C_{p r}}{C_{i n}} \cdot 100 \%,
$$

where $\mathrm{C}_{i n}$ - the solids content in the initial sludge, $\mathrm{kg} / \mathrm{m}^{3} ; \mathrm{C}_{p r}$ - the solids content in the liquid separation product (centrifuge centrate), $\mathrm{kg} / \mathrm{m}^{3}$.

The fluid velocity in the pipes is controlled by an ultrasonic flow meter. Sediment samples are taken from the cart from under the centrifugal unit to determine the moisture content of the sediment.

\section{4. Processing of experimental results}

Mathematical processing of experimental results is performed using the Statistica 7.0 software package, designed for statistical processing of experimental research data. The data obtained are processed by establishing the dependence of the response on independent variables, presenting them in a graphical form and constructing regression models for the given parameters on the basis of this.

In the regression analysis, the task is to search for the functional dependence of the mathematical expectation $M(Y)$ on the values of the given factors $\mathrm{X}: M(Y)=f(X 1, X 2)$.

The primary results of flocculation cleaning experiments are plotted on 3D graphs in the $Z-Y-X$ coordinates: flocculant consumption, $g / t$ - floccule sedimentation time after mechanical action, $\mathrm{mm} / \mathrm{s}$ - solid phase concentration in the sludge, $\mathrm{g} / \mathrm{l}$. The dependence of the flocculant flow rate is presented by a second-order model in the form of a square polynomial equation of the obtained response surface, which corresponds to the methods described in [22].

\section{The results of a study of the effectiveness of cleaning and dehydration of fine sludge} 3. 1. The results of the study of the optimal operating conditions of the module

An analysis of wastewater containing a polydisperse solid phase of various concentrations using the example of a metallurgical enterprise [20,21] and a coal preparation plant [19] makes it possible to construct the following relationships shown in Fig. 2. 


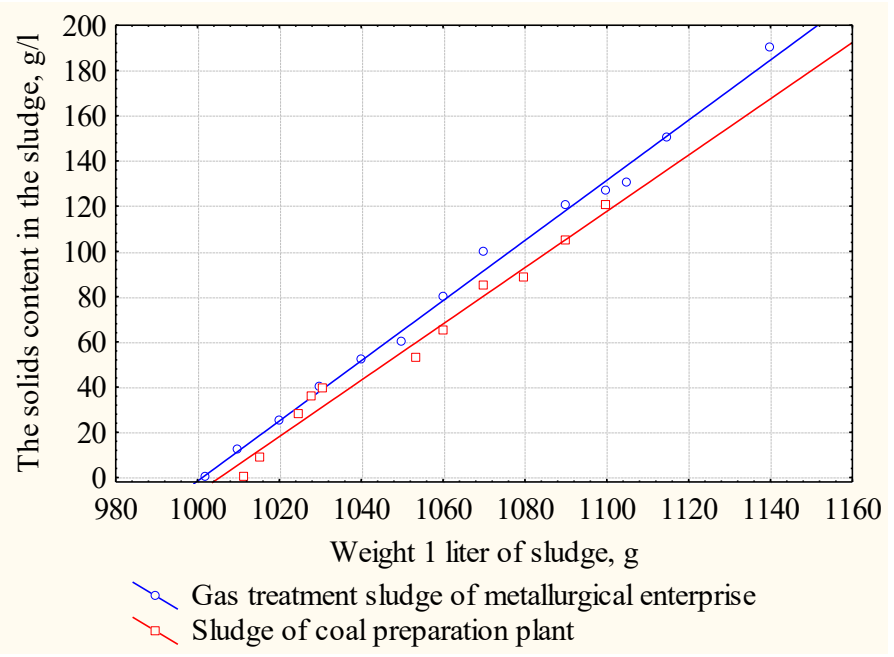

Fig. 2. The dependence of the solids content on the weight of the sludge for the samples

As can be seen from Fig. 2, the specific gravity of pure water without solid phase impurities exceeds $1000 \mathrm{~g} / \mathrm{l}$ due to dissolved salts. With increasing concentration of the solid phase, the density of the wastewater sample (suspension) increases. It should be emphasized that depending on the conditions of a particular production (amount of dissolved salts, density of the solid phase) for each enterprise, the dependence of the density on the concentration of the solid phase in the suspension can be established empirically. The construction of similar relationships for the sludge of a particular enterprise allows to quickly control the concentration of the solid phase in the wastewater at the entrance to the treatment plant by simply weighing a sample of 1 liter. As a result of the analysis of the data (points in Fig. 2), the equation of the dependence of the concentration of solid phase $C$ on the mass of one liter of sludge $m$ can be represented in the form of formulas convenient for recalculation:

$$
\begin{aligned}
& C_{1}=-1330+1,33 \cdot m, \\
& C_{2}=-1250+1,24 \cdot m,
\end{aligned}
$$

where $C_{1}$ and $C_{2}$ - the concentration of the solid phase in the sludge of the metallurgical plant and coal preparation plant, respectively.

The results of an experimental study of the dependence of the deposition rate of flocs in wastewater samples and model sludge on the concentration of the solid phase and the dose of flocculant are presented in Fig. 3.

Analysis of Fig. 3 shows that in the presence of fluctuations in the concentration of the solid phase, in order to achieve a certain rate of deposition of flocs, it is necessary to adjust the supply of flocculant. This means that after mechanical action (strength criterion of flocs $V_{2}$ ), the flow of the flocculant should be changed in accordance with the change in concentration.

Based on the statistical processing of the data presented in Fig. 3, one can obtain response surface equations taking into account the dependence of the flocculant dose $Q$ on the expected velocity $V_{2}$ at various concentrations of the solid phase in sludge $C$ :

$$
\begin{aligned}
& Q_{1}=83,6-14,3 \cdot \mathrm{C}+54,2 \cdot V+0,503 \cdot \mathrm{C}^{2}+2,06 \cdot \mathrm{C} \cdot V-4,41 \cdot V^{2}, \\
& Q_{2}=149,74-21,13 \cdot V-1,02 C+6,93 \cdot V^{2}+0,17 \cdot \mathrm{C} \cdot V+0,05 \cdot \mathrm{C}^{2},
\end{aligned}
$$

where $Q_{1}$ and $Q_{2}$ - the flocculant consumption in the sludge of the metallurgical enterprise and coal preparation plant, respectively. 


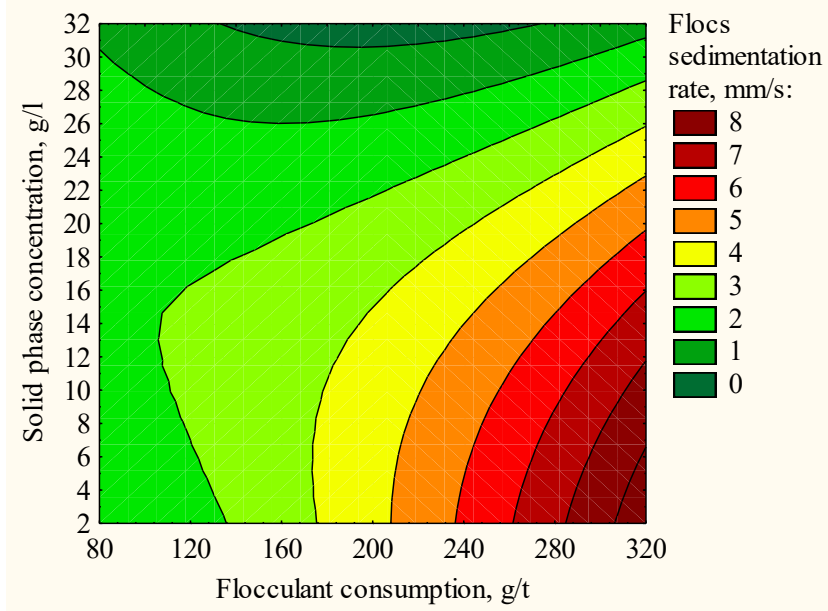

$a$

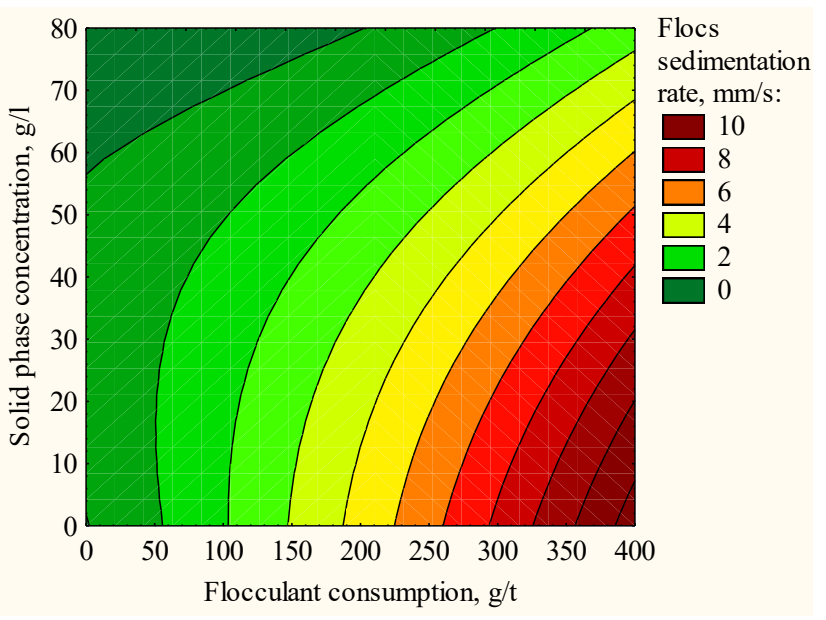

$b$

Fig. 3. Dependence of the flocculant flow rate and on the concentration of the solid phase in order to achieve the floccule sedimentation rate after hydromechanical action for $40 \mathrm{~s}$ at a sludge speed of up to $2 \mathrm{~m} / \mathrm{s}: a$-wet sludge of a metallurgical enterprise; $b$ - sludge of a coal preparation plant

An analysis of equations (6) and (7) shows that the dependence of the flocculant flow rate on the concentration of the solid phase is not linear and requires constant monitoring and preliminary studies. The methods for conducting laboratory tests and constructing such dependencies are described in more detail in [19-21].

A similar dependence can be obtained for any other sludge of a particular production and take into account not only the concentration of the solid phase, but also, for example, particle size or other factors affecting the efficiency of flocculation. However, when building dependencies, it is necessary to achieve the adequacy of a laboratory test for flocculation. That is, the intensity (average speed of the movement of the sludge) and the mixing time of the flocculant in the laboratory test when determining $V_{1}$ should correspond to the actual conditions on the module. The residual strength of the flocs that $V_{2}$ characterizes in the laboratory test should also be determined with appropriate intensity and mixing time. To control the adequate operation of the apparatus circuit in this particular case, the mixing time of the sample in the test is 40 seconds and was equal to the time the fluid flows through the sump at a given capacity. The intensity of mixing was selected so that the fluid velocity was approximately $2 \mathrm{~m} / \mathrm{s}$ and corresponded to the velocity of the sludge velocity in the pipes. In turn, the sludge velocity depends on the performance of the feed and the diameter (section) of the pipes. By changing the productivity of the inlet sludge or the cross-sectional area of the tubular flocculator, it is possible to control the flow rate during transportation of the flocculated sludge. 
When debugging the operating modes of the Module, difficulties are noted in connection with the manual adjustment of the supply of flocculants and changes in pulp consumption, which is excluded during the operation of the automated control system of the industrial Module. Despite these difficulties, in most cases, adjusting the supply of flocculant when changing the concentration of the solid phase in the diet led to the achievement of the expected cleaning efficiency.

\section{2. Results of industrial tests of the Module}

In the course of industrial experiments, it is found that the introduction of a flocculant in two portions leads to the formation of more durable flocs than in one at the same flow rate. The first portion should contain a dose of flocculant capable of forming small flakes without the formation of settling flocs. It is experimentally established that the optimal amount of flocculant in the first portion should be $30-40 \%$ of the total dose calculated according to Fig. 3. It is found that after the introduction of the second portion of the flocculant, the flow time of the flocculated sludge to the sump should be $8-10$ seconds (flocculation aggregation time). With an increase in mixing time of more than 10 seconds (due to an increase in the length of the flocculator or a decrease in the feed rate of sludge for cleaning), the destruction of the formed flocs and a decrease in their deposition rate in the sump are observed. When reducing the mixing time after the introduction of the entire dose of flocculant less than 8 seconds, the process of particle aggregation does not have time to complete. As a result of these processes, aggregates of unformed or already destroyed aggregates of a smaller size than in a laboratory test were delivered to the sump. As a result, solid phase contamination of the overflow of the sump is observed, instead of clear, clarified water.

In a series of industrial experiments, the cleaning module worked with a sludge flow rate of about $40 \mathrm{~m}^{3} / \mathrm{h}$. The sump operated continuously with a condensed product throughput of $10-15 \mathrm{~m}^{3} / \mathrm{h}$ with overflow of clarified water $25-30 \mathrm{~m}^{3} / \mathrm{h}$. Practice has shown that the condensed product for these types of sludge should be discharged continuously in an amount of $25-30 \%$ of the total volume. A large degree of thickening is impractical, since it leads to a decrease in the strength of the flocs during compaction of the sediment in the sump.

The efficiency of removing the solid phase in the centrifuge in the sediment and the moisture content of the sediment depend on the strength of the flocs, which can be estimated by the residual deposition rate before the centrifuge. Fig. 4 shows the results of industrial tests of the Module on real industrial sludge.

The obtained dependences of the retention degree of the solid phase $\eta$ and sediment moisture $W$ on the strength criterion of flocs $V$ can be represented in the form of the following equations of approximating curves:

$$
\begin{gathered}
\eta_{1}=-6,53+110 \cdot V-38,7 \cdot V^{2}+4,52 \cdot V^{3}, \\
W_{1}=52,2-21,2 \cdot V+3,85 \cdot V^{2}, \\
\eta_{2}=26,2+31,66 \cdot V+2,44 \cdot V^{2}-1,67 \cdot V^{3}, \\
W_{2}=45,5-5,3 \cdot V+0,565 \cdot V^{2},
\end{gathered}
$$

where $\eta_{1}, \eta_{2}$ - removal degree of the solid phase in the sludge of a given metallurgical production and coal preparation plant, respectively; $W_{1}, W_{2}$ - humidity of the centrifuge sediment during sludge dehydration for the studied metallurgical production and coal preparation plant, respectively.

Fig. 4 shows that in case of untimely adjustment of the supply of the optimal amount of flocculant with a change in the concentration of the solid phase in the nutrition of the Module, a decrease in the value of the residual strength of the flocs is observed. This leads to a decrease in the retention degree of the solid phase in the centrifuge and greater contamination with the solid phase of the centrate. With well-functioning flocculant dosing and timely monitoring of the operational efficiency parameters of each apparatus, it is possible to achieve a high degree of solid phase capture up to $97-99 \%$ and to obtain a pure centrate with a solid phase concentration of not more than 
1-2 g/l without additional flocculant supply before the centrifuge. A sufficiently high efficiency for sludge cleaning and sludge dewatering in a centrifuge of this type is achieved with a floccule strength criterion of $2-2.5 \mathrm{~mm} / \mathrm{s}$. Increasing the residual strength of the flocs is impractical, since this leads to an excessive consumption of the flocculant without a noticeable increase in the criteria for the effectiveness of sludge cleaning and dehydration.

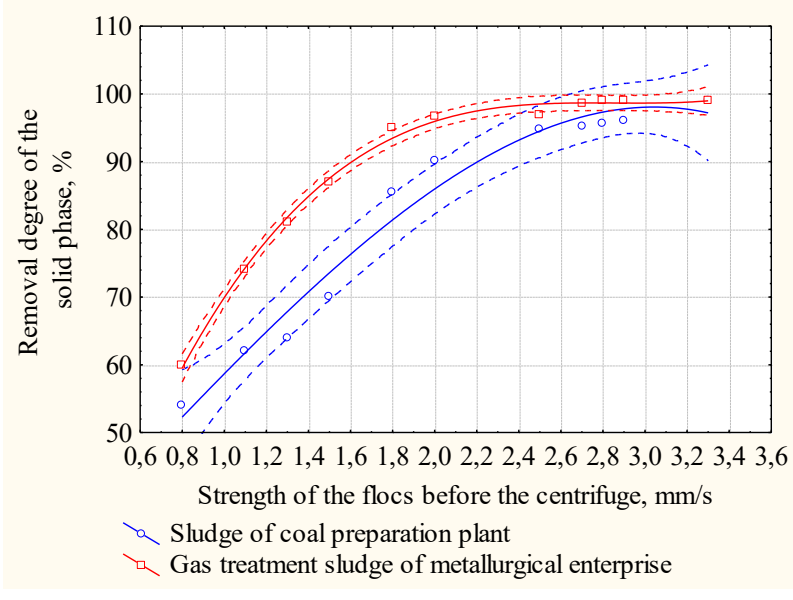

$a$

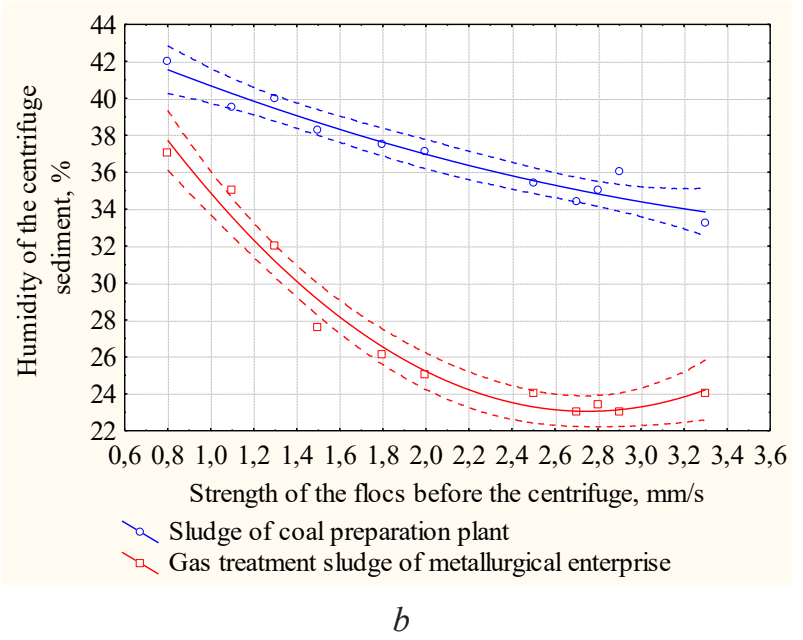

Fig. 4. The results of the treatment of sludge on the module for sludge cleaning and dewatering: $a$-dependence of the degree of removal of the solid phase from the strength of the flocs;

$b$-dependence of the moisture content of the sediment from the strength of the flocs

\section{Discussion of the research results on sludge cleaning and dehydration}

During industrial tests, studies are conducted on the operation of the module for cleaning and dewatering sludge in the apparatus circuit: flocculator - sedimentation tank - centrifuge. It is revealed that the adjustment of the chain of sewage treatment apparatus (selection of flocculants, pipeline length, productivity) should be based on technological tests. The criterion for optimizing flocculation treatment is the minimum consumption of reagents at the maximum efficiency of cleaning and dehydration of this type of sludge. In this case, one can take into account the following methodology for setting the indicated device circuit.

Firstly, it is necessary to select the amount of flocculant that is optimal both for cleaning the sludge in the sump and for dewatering the sludge in a centrifuge. For these purposes, it is necessary to identify the dependence of the flocculant consumption on the concentration of the solid phase and the residual velocity of the flocs (floccule strength criterion $V_{2}$ ). Moreover, it should be borne in mind that the change in the dose of the flocculant is not proportional to its concentration, but 
is described by polynomial dependencies, as shown in Fig. 3. The flow of flocculant during the operation of the equipment should be regulated in accordance with the change in the concentration of solid phase in the sludge. Calculation of flocculant consumption can be carried out using dependencies constructed by analogy with the derivation of equations (6) and (7).

Secondly, it is necessary to establish the dependence of the cleaning efficiency and the degree of sludge dewatering on the residual strength of the flocs. For a certain type of equipment and specific sludge, it is required to maintain a different value of the strength criterion of flocs. According to the results presented in Fig. 4, a satisfactory criterion for the strength of flocs can be considered $2.5 \mathrm{~mm} / \mathrm{s}$ for sludge from a coal preparation plant and $2.0 \mathrm{~mm} / \mathrm{s}$ for wastewater from metallurgical industries. The obtained values of the floccule strength criterion for this particular case can be substituted in dependences (6) and (7) and the dosage of concentration can be calculated taking into account only the change in concentration at the inlet.

Thus, in the process of setting up the operation of the apparatus chain during wastewater treatment, it is necessary to determine the strength criterion of the units, which ensures high-quality cleaning and dewatering of sludge in the final apparatus (centrifuge). Then, based on this value, select the amount of flocculant, taking into account the variable concentration of the solid phase at the inlet.

Thirdly, it is necessary to select the best conditions for the aggregation, that is, the conditions under which durable aggregates are formed with a minimum consumption of flocculant. These conditions include the concentration of the solid phase of the sludge, the time and intensity of mixing and transportation. The concentration at the input should be monitored promptly, for example, as shown in Fig. 2 for measuring the mass of a sample of sludge. At the same time, the analysis of Fig. 3 shows that increasing the concentration of the solid phase above a certain limit leads to an increase in flocculant consumption by several times. The reason for this is poor-quality mixing of the flocculant in a concentrated suspension. However, most of the solid particles do not interact with the flocculant with the formation of bridges. This suggests the need to adjust the sludge by diluting it with purified (clarified in the sump) water to a concentration at which the flocculant mixes well enough. The concentration of the solid phase before the supply of the flocculant according to Fig. 3, $\boldsymbol{a}$ for sludge from gas purification of a metallurgical enterprise, it is necessary to maintain no higher than $20-25 \mathrm{~g} / \mathrm{l}$, for sludge from coal preparation, in accordance with Fig. 3, $\boldsymbol{b}$ no higher than 50-60 g/l. At these concentrations, the flocs strength criteria are achieved without flocculant overspending.

The disadvantage of the approaches described in the article is that the research and testing data are presented on the example of only two types of sludge from coal preparation and metallurgical production. An advantage of the described methods is that the proposed methodology for optimizing the treatment and dewatering of sludge during their flocculation can be adapted and applied to other types of sludge or equipment.

\section{Conclusions}

The tests of the Module for wastewater treatment and dewatering of fine sludge confirm the satisfactory operation of the apparatus in a production environment. During industrial tests, it is found that the flocculation time to the sump should be in the range of $8-10 \mathrm{~s}$, and the sump should operate continuously with the output of condensed sludge in the amount of $25-30 \%$ of the working capacity for power.

During the testing of the Module for wastewater treatment and dehydration of fine wastes of the coal processing plant under study, a sludge treatment efficiency of $99 \%$ with dehydrated product moisture of up to $36 \%$ is achieved with a floccule strength criterion of $2.5 \mathrm{~mm} / \mathrm{s}$ in front of a centrifuge. When cleaning wet sludge from a metallurgical plant, sludge treatment efficiency of $97 \%$ is achieved with a dehydrated product humidity of $25-26 \%$ with a floccule strength criterion of $2.0 \mathrm{~mm} / \mathrm{s}$ in front of a centrifuge. At the same time, flocculant consumption is up to 150-200 g/t.

The conditions for the high efficiency of the operation of the apparatus chain described in this article are control of the flocculation efficiency and the residual floccule deposition rate after mechanical action. For these purposes, a methodology for conducting technological tests is proposed. The intensity and time of exposure to flocs should correspond to the operating conditions of the circuit of the apparatus of the Module. Such conditions may include sludge productivity, sludge flow rate in the cross section of pipes and apparatuses, flow time from the flocculator to the centrifuge. 


\section{References}

[1] Shevchenko, A. I., Bubnova, E. A. (2015). Perspektivy i problemy perevoda shlamonakopiteley Ukrainy v kategoriyu tehnogennyh mestorozhdeniy. Zbahachennia korysnykh kopalyn, 60, 162-169.

[2] Wang, C., Harbottle, D., Liu, Q., Xu, Z. (2014). Current state of fine mineral tailings treatment: A critical review on theory and practice. Minerals Engineering, 58, 113-131. doi: https://doi.org/10.1016/j.mineng.2014.01.018

[3] Sokur, A. K. (2012). Obzor gravitatsionnyh tehnologiy obogashcheniya ugol'nyh shlamov neflotatsionnoy krupnosti. Zbahachennia korysnykh kopalyn, 51 (92), 126-136.

[4] Mohanty, M. K. (2007). Screen Bowl Centrifuge Dewatering Process: A Parameteric Study. Physical Separation in Science and Engineering, 2007, 1-9. doi: https://doi.org/10.1155/2007/70376

[5] Tao, D., Parekh, B. K., Liu, J. T., Chen, S. (2003). An investigation on dewatering kinetics of ultrafine coal. International Journal of Mineral Processing, 70 (1-4), 235-249. doi: https://doi.org/10.1016/s0301-7516(03)00025-5

[6] Murphy, C., Bennett, C., Olinger, G., Cousins, B. (2012). Operation of the belt filter presses at the rockspring development preparation plant. Corrxan. Availale at: http://www.corrxan.com/Coalprep_2012_Paper.pdf

[7] Fan, Y., Dong, X., Li, H. (2015). Dewatering effect of fine coal slurry and filter cake structure based on particle characteristics. Vacuum, 114, 54-57. doi: https://doi.org/10.1016/j.vacuum.2015.01.003

[8] Hou, Y., Dang, J., Wang, L., Yang, X., Wang, X. (2014). The Data Processing System of Coal Slurry Pipeline Pressure Based on AMFL. 2014 International Symposium on Computer, Consumer and Control. doi: https://doi.org/10.1109/is3c.2014.207

[9] Reddy, K. R., Urbanek, A., Khodadoust, A. P. (2006). Electroosmotic dewatering of dredged sediments: Bench-scale investigation. Journal of Environmental Management, 78 (2), 200-208. doi: https://doi.org/10.1016/j.jenvman.2005.04.018

[10] Xian-shu, D., Xiao-jie, H., Su-ling, Y., Wei-peng, R., Zhi-zhong, W. (2009). Vacuum filter and direct current electro-osmosis dewatering of fine coal slurry. Procedia Earth and Planetary Science, 1 (1), 685-693. doi: https://doi.org/10.1016/j.proeps. 2009.09.108

[11] Wu, Z. H., Hu, Y. J., Lee, D. J., Mujumdar, A. S., Li, Z. Y. (2010). Dewatering and Drying in Mineral Processing Industry: Potential for Innovation. Drying Technology, 28 (7), 834-842. doi: https://doi.org/10.1080/07373937.2010.490485

[12] Ksenofontov, V. V., Makeev, I. I. (2014). Settling and Filtering Centrifuge for Dewatering of Coal Slack - Theory and Practice. Ugol', 12, 78-81.

[13] Bethell, P. J. (2004). Froth Flotation - To Deslime or Not to Deslime? CPSA Journal, 3 (1), 12-15.

[14] Parekh, B. K. (2009). Dewatering of fine coal and refuse slurries-problems and possibilities. Procedia Earth and Planetary Science, 1 (1), 621-626. doi: https://doi.org/10.1016/j.proeps.2009.09.098

[15] Shkop, A., Tseitlin, M., Shestopalov, O., Raiko, V. (2017). Research of ways to reduce mechanical influence on floccules in a centrifuge. Technology Audit and Production Reserves, 1 (3 (33)), 39-45. doi: https://doi.org/10.15587/2312-8372.2017.93690

[16] Oyegbile, B., Ay, P., Narra, S. (2016). Flocculation kinetics and hydrodynamic interactions in natural and engineered flow systems: A review. Environmental Engineering Research, 21 (1), 1-14. doi: https://doi.org/10.4491/eer.2015.086

[17] Hogg, R. (2000). Flocculation and dewatering. International Journal of Mineral Processing, 58 (1-4), 223-236. doi: https:// doi.org/10.1016/s0301-7516(99)00023-x

[18] Shkop, A., Tseitlin, M., Shestopalov, O., Raiko, V. (2017). A study of the flocculs strength of polydisperse coal suspensions to mechanical influences. EUREKA: Physics and Engineering, 1, 13-20. doi: https://doi.org/10.21303/2461-4262.2017.00268

[19] Shkop, A., Briankin, O., Shestopalov, O., Ponomareva, N. (2017). Investigation of the treatment efficiency of fine-dispersed slime of a water rotation cycle of a metallurgical enterprise. Technology Audit and Production Reserves, 5 (3 (37)), $22-29$. doi: https://doi.org/10.15587/2312-8372.2017.112791

[20] Shkop, A., Briankin, O., Shestopalov, O., Ponomareva, N. (2017). Investigation of flocculation efficiency in treatment of wet gas treatment slime of ferroalloys production. Technology Audit and Production Reserves, 5 (3 (37)), 29-39. doi: https://doi.org/ 10.15587/2312-8372.2017.112792

[21] Wang, Y., Chen, K., Mo, L., Li, J., Xu, J. (2014). Optimization of coagulation-flocculation process for papermaking-reconstituted tobacco slice wastewater treatment using response surface methodology. Journal of Industrial and Engineering Chemistry, 20 (2), 391-396. doi: https://doi.org/10.1016/j.jiec.2013.04.033

[22] Trinh, T. K., Kang, L. S. (2011). Response surface methodological approach to optimize the coagulation-flocculation process in drinking water treatment. Chemical Engineering Research and Design, 89 (7), 1126-1135. doi: https://doi.org/10.1016/ j.cherd.2010.12.004 